\title{
REVITALIZANDO O ESPAÇO DE ENCANTAMENTO E BUSCA PELO CONHECIMENTO EM UMA BIBLIOTECA PÚBLICA ESCOLAR: UMA EXPERIÊNCIA NA EXTENSÃO
}

\author{
REVITALIZING THE SPACE OF ENCHANTMENT AND THE SEARCH FOR \\ KNOWLEDGE IN A PUBLIC SCHOOL LIBRARY: AN EXTENSION EXPERIENCE
}

Nara Cristine Thomé Palácios Cechella ${ }^{1}$, Karoline Vanolli ${ }^{2}$, Maurício de Souza Brillinger ${ }^{2}$

\begin{abstract}
RESUMO
Este artigo traz a experiência de ex-acadêmicos de Letras em um projeto de extensão realizado em uma biblioteca de escola pública estadual. Na avaliação do acervo, constatou-se que nada estava catalogado e disponibilizado aos alunos. Objetivou-se a revitalização da biblioteca, a fim de democratizar o espaço para estudo, organizando o acervo para que todos usufruíssem do material atualizado, pensando-se no que a leitura e a pesquisa proporcionariam ao estudante; além disso, catalogar e informatizar a biblioteca. O projeto teve cinco etapas: reconhecimento do local e armazenamento do acervo; avaliação, retirada de livros em desuso para doação/reciclagem; realizada a separação dos livros para venda, revertendo o dinheiro para a compra de armário, para o uso discente; sugerida a reorganização do espaço da biblioteca à direção e catalogação do acervo. Após conversar com bibliotecárias e direção, realizou-se uma análise dos livros e o acervo foi avaliado. Os livros do professor foram realocados em estantes para consulta docente, separados por área. Descartaram-se os livros com edições inferiores a 2000, exceto os materiais com valor histórico/necessários na biblioteca. Os professores fizeram sua seleção e se doou o descarte. Os livros em desuso foram analisados também e, segundo a edição, o estado e o conteúdo, separados para doação/reciclagem. Após uma greve de 62 dias, finalizou-se a seleção dos materiais e iniciada a recatalogação dos materiais. Atualmente, verificou-se que o programa usado na informatização do sistema está desatualizado; o computador não funciona; o acervo aumentou e está acumulando, não havendo ninguém habilitado para atender aos estudantes.
\end{abstract}

Palavras-chave: Extensão; Revitalização; Biblioteca; Escola Pública.

\begin{abstract}
This article presents the experience of former academics of Letters in an extension project carried out in a public school library. In the evaluation of the collection, it was found that nothing was cataloged and available to students. It aimed to revitalize the library in order to

${ }^{1}$ SEAD - Setor de Educação a Distância. PROGRAD - Pró-Reitoria de Ensino de Graduação. UNA HCE Unidade Acadêmica de Humanidades, Ciências e Educação.

${ }^{2}$ Universidade do Extremo Sul Catarinense - UNESC.
\end{abstract}


democratize the space of study, organizing the collection for all in favor of enjoying updated material, thinking about what reading and research would provide to the student; additionally, to catalog and computerize the library. The project had five stages: recognition of local and collection storage; evaluation, removal of books in disuse for donation/recycling; performed the separation of books for sale, reversing the money to the cabinet purchase, for student's use; suggested the reorganization of the library space to the scholar direction and the collection cataloging. After talking with librarians and direction, it was done an analysis of the books and the collection was evaluated. The teacher's books were carried out on shelves for teaching consultation, separated by area. The books, with previous editions before 2000, except of materials of historical value/required in the library, were discarded. Teachers made their selection and donated the dispose. The books in disuse were analyzed and also, according to the edition, the status and content, they were separated for donation/recycling. After a strike of 62 days, the selection of materials was finalized and it was started to recataloging materials. Nowadays, it was found that the program used in the computerization of the system is outdated; the computer does not work; the collection has increased and it is accumulating, and there is nobody able to attend to the students.

Keywords: Extension; Revitalization; Library; Public school.

\section{INTRODUÇÃO}

Ao se falar em Biblioteca, a primeira - e talvez a principal - ideia que vêm à mente é a de um local silencioso com uma coleção imensa de livros e diversos outros documentos, devidamente registrados para consultas, leituras e estudo, além de muito pó. Lamentavelmente, é essa a realidade de muitas bibliotecas, principalmente, em escolas da rede pública estadual. A biblioteca ainda é vista como apenas um depósito de materiais.

Pensando nestes pontos, buscou-se um local que estivesse nestas condições. Os critérios levantados foram: a existência deste espaço em uma escola pública na cidade de Criciúma, preferencialmente da rede estadual. Após um levantamento das Unidades de Ensino da região, chegou-se à Escola de Educação Básica Engenheiro Sebastião Toledo dos Santos, conhecida como Colegião ou STS, por estar entre as cinco maiores escolas estaduais do Estado de Santa Catarina, sendo a maior do extremo sul catarinense, atendendo apenas o Ensino Médio, ou seja, com adolescentes e jovens de faixa etária entre 15 e 20 anos, moradores de diversos bairros da cidade, localizada no centro dessa cidade. Esses jovens, pela idade, pressupõem-se serem leitores e usuários da biblioteca, levando em conta o fato de estarem no Ensino Médio, preparando-se para vestibulares ou outros processos seletivos, a fim de ingressar no Ensino Superior e/ou no mercado de trabalho.

Em visita à escola, que completa 40 anos de existência em 2013, foi possível conhecer um pouco mais sobre a realidade vivenciada pela comunidade escolar. A biblioteca da E.E.B. 
Engo. STS existe há mais de três décadas. Possuía um acervo superlotado (Figura 1), com materiais encaixotados e amontoados pelos cantos e livros novos sem registro (Figura 2).

Figura 1. Livros em desuso

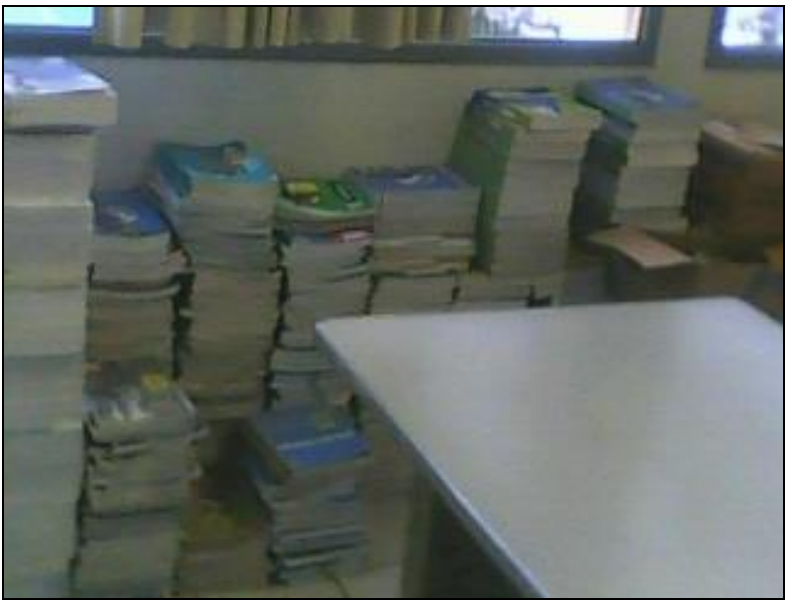

Fonte: Dos Autores, 2012.
Figura 2. Livros novos, encaixotados há mais de dois anos.

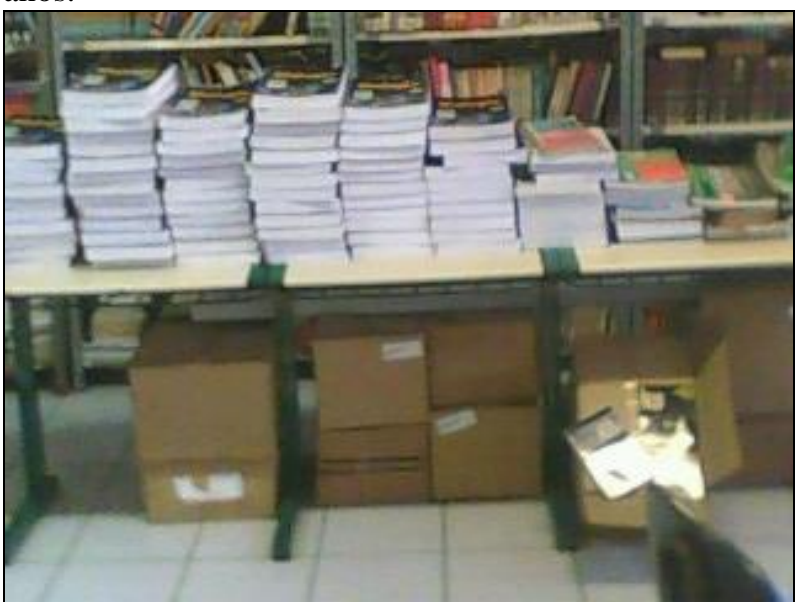

Fonte: Dos Autores, 2012.

A Biblioteca João Henrique Pestallozzi, registrada em 1982 (Figura 3), recebeu o nome deste educador por sua trajetória de vida, cheia de altos e baixos, um eterno sonhador por uma educação libertadora, de qualidade, enfrentando quaisquer desafios, incluindo as mudanças políticas, as quais caracterizam sua carreira profissional e, por isso, considerado mentor e reformador da escola popular, Pestalozzi, antes mesmo de a Psicologia ter surgido, já imaginava o ambiente escolar servindo a seus estudantes com princípios de uma educação renovada, cuja ideologia, transformada em missão, era a de complementar os ensinamentos da família e como preparação da educação para a vida.

Nascido em 1746 (Século XVIII), em Zurique, na Suíça, Johann Heinrich Pestalozzi era filho de reformados italianos que emigraram para esse país, no século XVII, era pedagogo e um humanista em sua essência. Sua filosofia de educação moderna prolongou-se até nossos dias. Para ele, os aspectos individuais afetivos e sociais entre o estudante e sua família são fundamentais para que o processo da educação formal, em um ambiente escolar, sejam realizados com sucesso. 
Figura 3. Registro da Biblioteca João Henrique Pestalozzi.

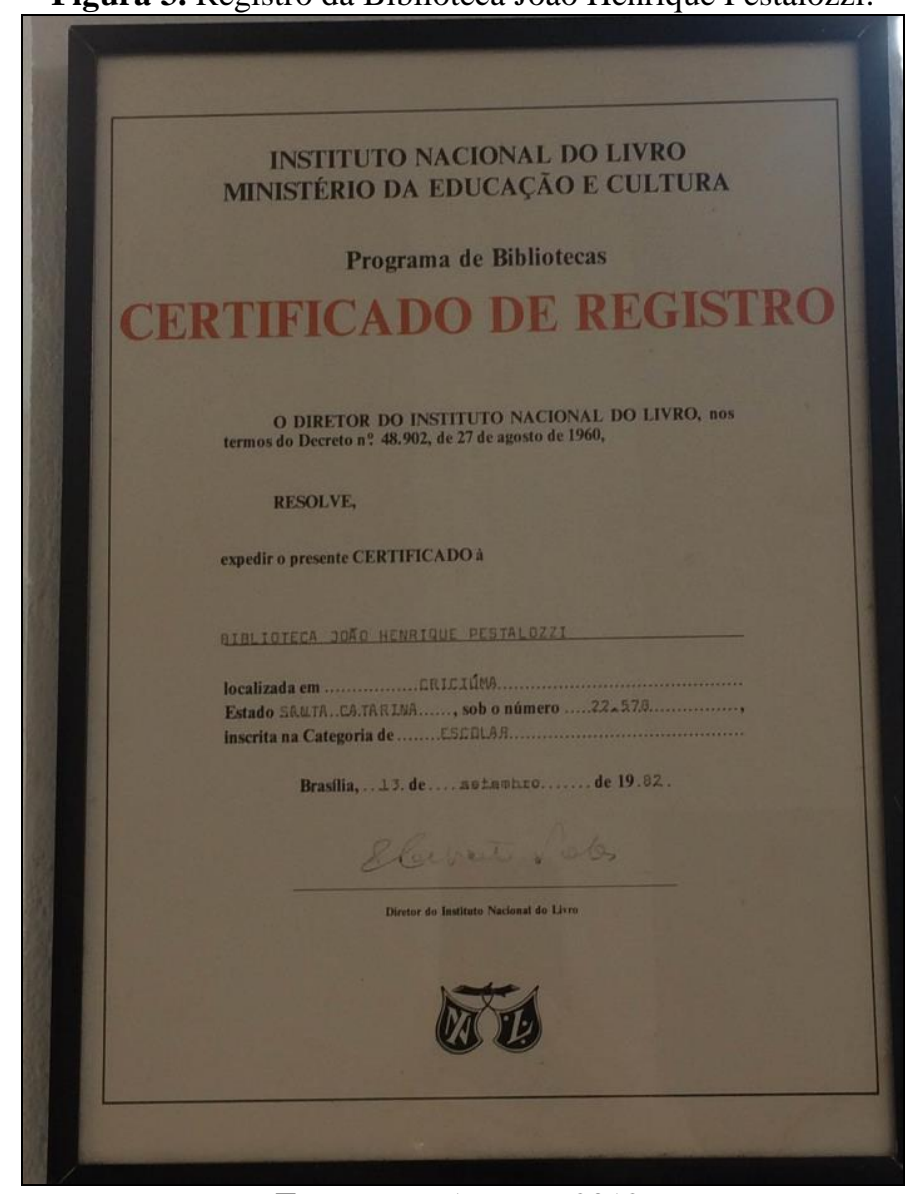

Fonte: Dos Autores, 2012.

Depois de fundar seu primeiro instituto de educação, acolhia e preparava rapazes pobres para um futuro melhor, com um currículo baseado em cálculo, leitura e desenho. Como eram do campo, ainda praticavam manufatura de fiação e trabalhos agrícolas, pois era com o trabalho dos alunos que mantinha o local e garantiam o sustento de todos os que ali viviam. Sem noções administrativas e endividado, Pestalozzi vai à falência, vira escritor e sua obra Leonardo e Gertrudes mostra os princípios e os aspectos de uma prática pedagógica eficientes, garantindo-lhe sucesso em sua primeira empreitada.

A Revolução Francesa, como em um efeito dominó, mexeu com a Suíça e, após a guerra, muitas crianças ficaram órfãs. Em 1798, houve uma transformação na vida desses pequeninos pelas mãos de Pestalozzi que, ao auxiliar o amigo Filipe Stapfer, então ministro de instrução e companheiro de uma associação filantrópica, pôde transformá-las física e moralmente em pessoas melhores, graças às suas teorias pedagógicas e métodos educativos. No entanto, mais uma vez, Pestalozzi frustra-se, pois a escola vem a fechar, a fim de abrigar um hospital militar. 
Sem desistir de sua vocação, um eterno sonhador, Pestalozzi ganhou fama por seus métodos por onde passava. Foi então que lhe cederam um castelo do século VII para fundar uma escola primária e uma escola normal. Abriu-o em 1800 e fez tanto sucesso que seu nome transpôs as barreiras suíças, levando seu prestígio por toda a Europa. Após três anos de sucesso, devido às mudanças políticas na Suíça, o educador precisou deixar o castelo.

Mudou-se para Iverdon, à beira do lago de Neuchâtel, em uma estância termal bastante conhecida naquela região. Lá, em outro castelo, este que pertenceu a Carlos Temerário, que Pestalozzi, já no fim de sua carreira (em 1805), realiza sua obra educativa que o eterniza no rol dos pedagogos. É ali naquela cidade, onde o sistema praticado era ainda o de castigos corporais e recompensas, que ele introduz a cultura física, com preceitos de higiene e aulas individuais de acordo com as aptidões dos alunos, imortalizando seu nome, inclusive, com seu livro O Canto dos Cisnes, publicado em 1926, avaliado como um testamento pedagógico. Nele, Pestalozzi afirma que a formação do caráter é mais importante que a aquisição de conhecimentos; ou seja, "a educação ou a superioridade do valor do ser humano sobrepõe-se à instrução ou ao conteúdo cultural" (AZEVEDO, 1972, p. 33). No artigo, há uma reflexão bastante interessante:

A Escola não poderá vencer nem atenuar as carências que provêm do berço como sejam a preguiça, a indolência e os sintomas de concupisciência. Apesar das recompensas e dos castigos dos professores, a formação do caráter do educando não atingirá a perfectabilidade que é apanágio do ambiente familiar. Apenas o recuro à educação religiosa seria o meio apropriado de conjugar aqueles vícios - pensava ainda Pestalozzi dentro do condicionalismo social do seu tempo. $<<$ A orientação da família está ìntimamente ligada à Escola e ao que nela se ensina >> - escrevia ele (AZEVEDO, 1972, p. 37).

De acordo com seus discípulos e colaboradores, as principais ideias da pedagogia Pestalozziana estão registradas em uma obra intitulada A Pedagogia do século XVIII. Outra obra sobre o educador João Henrique Pestalozzi, de Soëtard (2010, p. 35), traduzida para o português, apresenta suas ideias, sobre as quais ele primava por uma educação humana com base na natureza espiritual e física da criança; uma educação que a desenvolvesse internamente, espontaneamente, mas sob certa direção; uma educação que se baseasse nas circunstâncias em que o ser humano se encontra; uma educação social, com a escola popular; educação profissional e uma educação religiosa não-confessional.

Após conhecer a vida pregressa, os princípios de Pestallozzi e suas contribuições ao ensino público, bem como o porquê ter sido homenageado nomeando a biblioteca desta U.E., passou-se a verificar como era o quadro funcional deste setor e se condizia com toda a 
teorização descrita acima, ou seja, se o perfil dos funcionários estaria em consonância ao projeto a ser executado naquele espaço.

É mister destacar que um projeto como este, de revitalização de espaço bibliotecário e avaliação de obras, não é bem visto àqueles que não se dispõem a enfrentar mudanças, mas é imprescindível que seja feito. Há que se ter ânimo, disposição e desejo de mudança. A biblioteca dessa Unidade Escolar possuía um espaço que nunca havia passado por uma inspeção, fazendo-se urgente o encontro de lugares alternativos, realocação de coleções, retirada de materiais em desuso para depósito ou doação, revitalização de estantes...

A Biblioteca Escolar deveria tornar-se "o coração da escola", um centro dinâmico, que atuando em consonância com a sala-de-aula participaria em todos os níveis e momentos do processo de desenvolvimento curricular, composto de um acervo de material de ensino e de leitura diversificado, organizado, acessível a alunos e professores e adaptado às aspirações do momento. Desempenharia na escola, mais ou menos o papel da Biblioteca Pública na comunidade (QUINHÕES, 1999, p. 178).

Além dos problemas físicos, o espaço não conta com um profissional preparado para lidar com o universo que é uma biblioteca. Hoje, há um rodízio de professores readaptados, que não possuem quaisquer vínculos com a dinâmica exigida ali. Não era raro encontrar à frente da biblioteca pessoas incapacitadas ou sem a devida formação para a tarefa de organizar este ambiente.

Antigamente, o professor não tinha outro auxílio além do livro adotado; e, fazer decorar a lição era a última palavra da pedagogia. [...] Daí, a necessidade de repensar o planejamento escolar como um processo contínuo-participativo do professor regente, bibliotecário e equipe técnico-pedagógica para reestruturar as funções da biblioteca na escola (QUINHÕES, 1999, p. 178).

Para começar a mudar esta realidade, a elaboração deste projeto foi uma das alternativas. Ele visava à coparticipação dos estudantes e docentes desta instituição, bem como a de funcionários e demais interessados em contribuir com a melhoria do ensino público. De forma alguma se pretendeu cumprir com o papel que cabe às autoridades políticas, mas sim, de ajudar a fortalecer os vínculos entre alunos, professores e materiais já existentes, mas que não eram bem aproveitados, seja por falta de pessoal especializado para organizar a biblioteca, seja por problemas do acervo. Era preciso conscientizar e estimular corpo discente e corpo docente para que não o utilizem como depósito de materiais ou como local para castigo dos que não se comportam bem em sala de aula.

A atitude que este grupo tomou, frente aos desafios presentes, mais precisamente em uma biblioteca interna de escola da rede pública estadual, por si só já era um dos motivos que 
justificam este projeto. Entrar em um ambiente dominado pela precariedade física, material e pessoal era outro ponto (Figura 4).

Figura 4. Estado físico do ambiente ${ }^{3}$ em que está localizada a biblioteca.

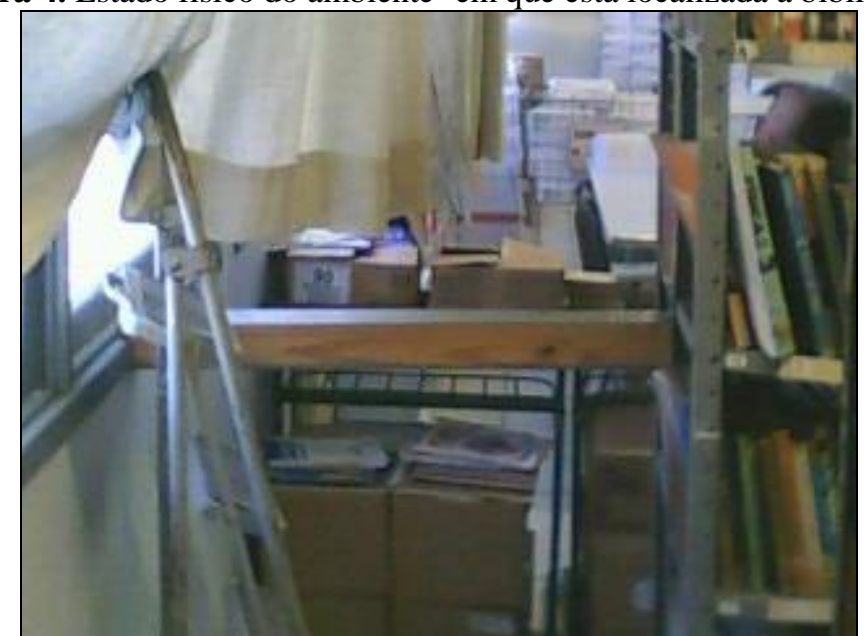

Fonte: Dos autores.

Fez-se necessário sentar com os responsáveis pela gestão escolar, adentrar a biblioteca e, de forma sistematizada, rever livros de registros, listas de materiais enviadas pela Secretaria de Educação, conferir com o que havia nas prateleiras - já em péssimo estado (Figura 5) - e avaliar se o que existia ali, de fato ainda fazia sentido ou estava em desuso. Esta foi a primeira parte da revitalização: a checagem.

\footnotetext{
${ }^{3}$ Ao fundo, livros novos que chegaram à instituição, todos no chão, amontoados, tomando espaço das mesas de estudo. No meio, carteiras de sala de aula limitando o acesso aos livros nas estantes apenas aos profissionais que trabalham na escola. Em primeiro plano, uma escada fora do depósito e uma tora de madeira para apoiar as estantes deste corredor à parede da janela, para que não caiam com o peso dos materiais.
} 


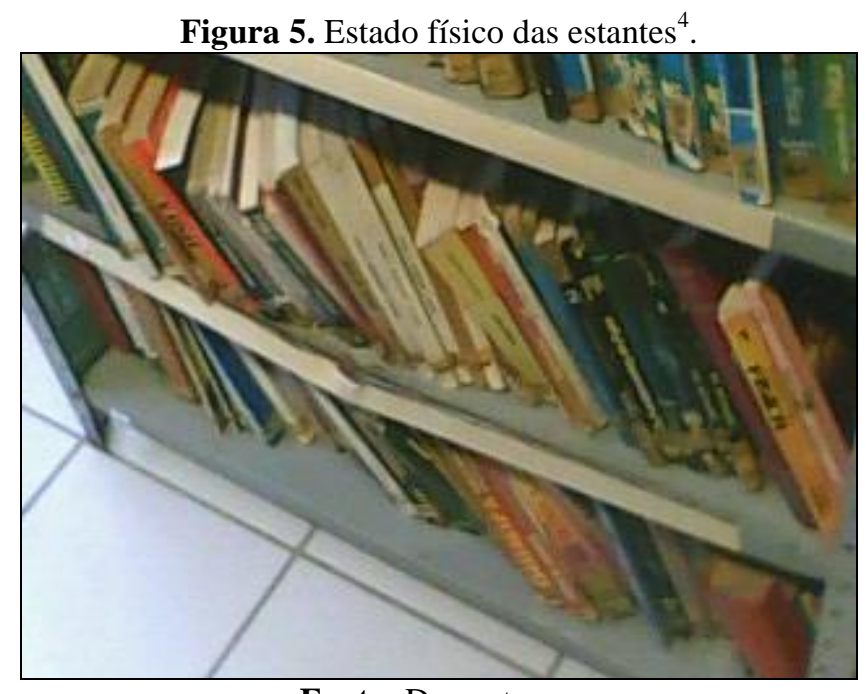

Fonte: Dos autores.

Em um segundo momento, pensou-se em estratégias motivacionais para que os alunos fizessem as carteirinhas e pudessem se sentir à vontade, estimulados a entrar novamente neste ambiente que deveria ser o espaço do lúdico, da busca do conhecimento, do trabalho em grupo, da pesquisa, talvez com a mudança do layout e a colocação de um armário com escaninhos, para que deixassem seus pertences, por exemplo, para começar.

Por último, após a organização do espaço, o grupo pensou em como garantir que o livro didático voltasse à biblioteca (Embora já existam campanhas na televisão, pelo Governo Federal, sobre os livros didáticos que devem ser devolvidos para que outros alunos usem-nos no ano letivo seguinte).

Quanto aos paradidáticos, e demais materiais disponibilizados no acervo, também se refletiu uma forma de garantir sua devolução, para que nada se perdesse e que o aluno soubesse lidar com a obra, demonstrando carinho e respeito ao próximo usuário do material. Além disso, pensou-se em uma campanha voltada ao estímulo pela leitura, a fim de que os alunos cresçam efetivamente como cidadãos emancipados, com consciência intelectual e crítica.

Observe-se que a Unesco colocou a Biblioteca Escolar entre os objetivos prioritários de sua atuação em favor das bibliotecas. "É preciso criar um ambiente favorável à leitura para se conseguir uma sociedade consciente dos benefícios que lhe podem advir da leitura e no qual os livros estejam ao alcance de todos." (ORGANIZAÇÃO das Nações Unidas para a Educação, Ciência e Cultura. Declaração de Londres: para

\footnotetext{
${ }^{4}$ Estantes tortas, enferrujadas, em desequilíbrio, quase tocando o chão pelo peso dos livros e vários materiais fora do contexto didático-pedagógico, ou seja, desatualizados, os quais já deveriam ter sido dado baixa e retirados deste espaço, dando lugar aos novos, ainda encaixotados.
} 
uma sociedade que lê. Londres, 7 a 11 de junho, 1982. 3p) (QUINHÕES, 1999, p. 179).

Para ter uma ideia de como estava a biblioteca antes do início do projeto, é possível observar as mudanças no quadro comparativo de imagens a seguir:

Quadro 1. Comparação do estado físico da Biblioteca Escolar.

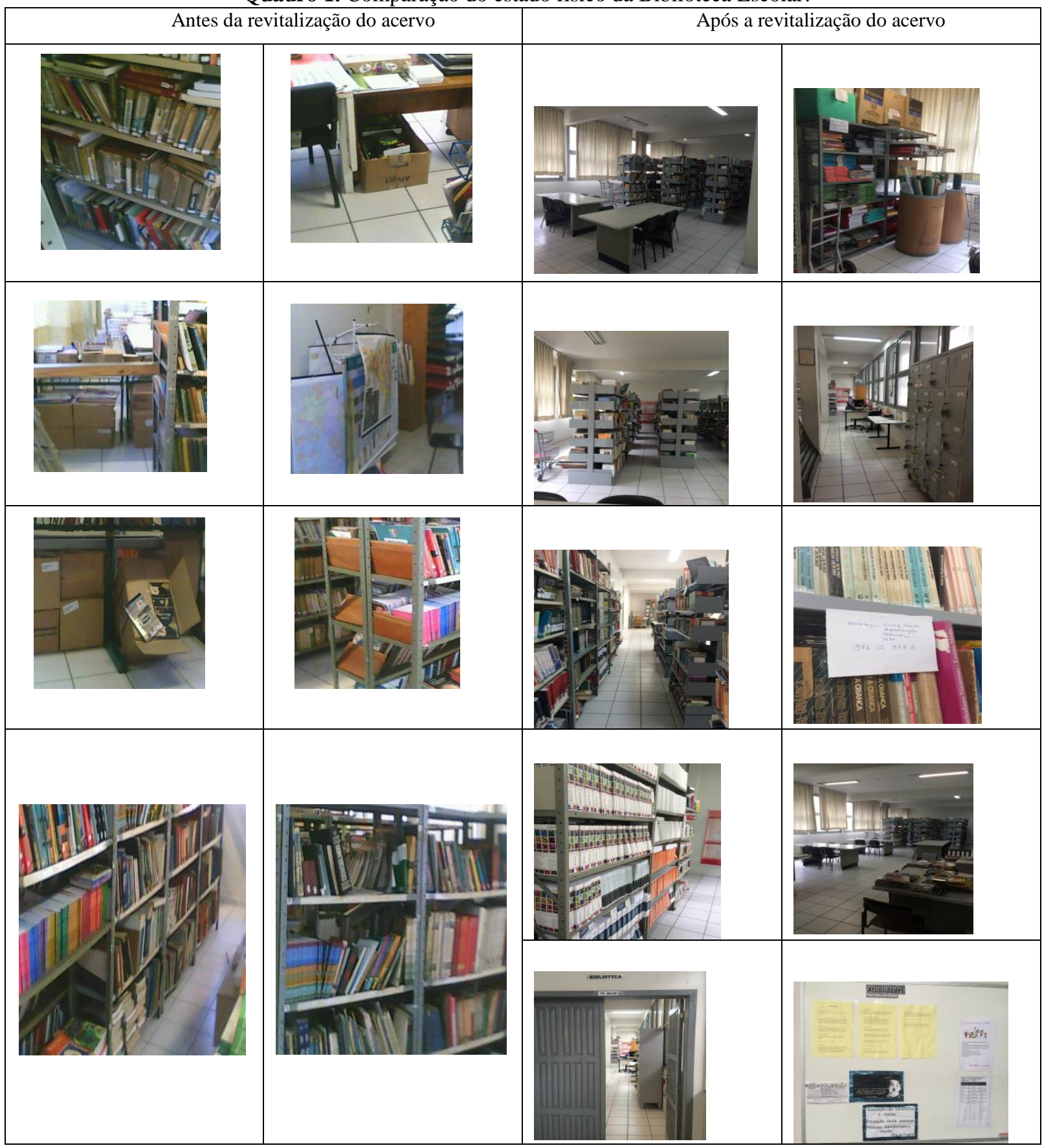

Fonte: Dos Autores. 
Muitas escolas da rede pública recebem alunos que vivem diferentes realidades, inclusive, em situação de risco. As ações implantadas objetivaram ajudar no incentivo e promoção do desenvolvimento intelectual, por meio de um ambiente mais atrativo, organizado, revitalizado e que promovesse a inserção dos alunos no mundo da informação, da Literatura, com um suporte bem estruturado, que atendesse às necessidades de sala de aula, complementadas pela leitura e pesquisa.

Os objetivos traçados para o desenvolvimento do projeto tiveram, com Geral: promover a revitalização de uma biblioteca escolar pública da rede estadual, incentivando a leitura, democratizando o espaço mobiliário para grupos de estudo, organizando o acervo para que todos possam usufruir de todo o material de forma simples e rápida, em um ambiente informatizado, voltando a pensar no encantamento que a leitura e a pesquisa podem proporcionar ao estudante. Como Específicos: 1 - Identificar nos registros da escola, qual o acervo atual da U.E.; 2 - Após a avaliação do acervo escolar, listar critérios de seleção para manter ou descartar o material em desuso; 3 - Informatização do acervo, com possibilidade de registrar das obras utilizando o recurso da catalogação CDU - Classificação Decimal Universal, a fim de viabilizar o encontro do material com maior facilidade e organização das obras; 4 - Orientar profissionais da escola para que possam encontrar títulos modernos, fazendo com que a procura por este ambiente seja fruto do estímulo à leitura e do hábito de ler e consultar o acervo para atividades disciplinares e extra-classe; 5 - Disponibilizar listagem atualizada do acervo para que docentes e discentes possam, de fato, conhecer o que a Biblioteca dispõe; 6 - Estimular a leitura em um ambiente melhor preparado para receber professores, alunos e funcionários da Unidade de Ensino; 7 - Após a finalização do projeto, produzir artigo científico a ser apresentado em congresso.

O público-alvo atendido foi a comunidade escolar da Escola de Educação Básica Engenheiro Sebastião Toledo dos Santos, pertencente à rede estadual de educação (Professores e ex-professores, alunos e ex-alunos e demais funcionários que utilizam este espaço da Instituição de Ensino), localizada na cidade de Criciúma, Bairro Comerciário, Santa Catarina. Além disso, o projeto alcançou, também, acadêmicos de cursos a distância da Udesc, cuja instituição possui uma sala para atendimento presencial nessa Unidade Escolar. 


\section{PROCEDIMENTOS METODOLÓGICOS}

O projeto foi organizado de modo a resolver, em princípio, três problemas:

1) Revitalização do acervo bibliográfico, com informatização e revisão documental sobre títulos a serem descartados;

2) Preparação de estratégias motivacionais para que o aluno/professor freqüente a biblioteca de fato, contando com a participação de todos na preparação de uma campanha para que os estudantes motivem-se a fazer as carteirinhas, e

3) Encontrar uma estratégia, a fim de que os alunos garantam a devolução dos livros em atraso. Estas últimas duas informações poderão a vir compor um caixa próprio da biblioteca para pequenas despesas da própria biblioteca, sem depender diretamente do Governo Estadual.

Por meio de um levantamento dos registros feitos em livros-ata, com todas as informações recebidas pelo Governo do Estado de Santa Catarina, foram definidos, juntamente com a Direção, os critérios de registros a serem atualizados, qual parte do acervo era possível dar baixa, a fim de melhorar os materiais a serem disponibilizados pela biblioteca escolar.

Dentre outras ações, esta foi a principal atividade esperada pela Direção da Escola, que mostrou sentir a necessidade de uma reavaliação do acervo (fazendo conferência rigorosa do que chegou à escola, registrado em livro e disponibilizado ao aluno, dando baixa nas obras em desuso, a fim de retirá-las das prateleiras para doação ou outro fim.); e de possível revitalização do layout e estandes, com bancas mais atrativas, com títulos de obras diversificadas.

Outro pedido feito, pela necessidade que se mostrava presente e gritante nesta escola, foi o fato da falta de informatização do acervo, que poderia ser feita após ou concomitantemente à etapa já descrita anteriormente.

Com a experiência dos bolsistas e todo o trabalho desenvolvido na Unidade Escolar, buscou-se a realização de todas as etapas acima descritas, a fim de que o projeto obtivesse êxito.

\section{DESENVOLVIMENTO}

Para desenvolver as atividades, foi estabelecido um cronograma de atividades a serem desenvolvidas no projeto de extensão, que, em princípio, não encontraria nenhum problema 
junto à escola. A maioria dos itens elencados nesse cronograma provisório inicial foi realizada com êxito: foram feitas reuniões, visitas prévias ao local onde o projeto seria implantado, análise dos registros da biblioteca e do acervo. No entanto, uma greve estadual de 62 dias ininterruptos fez com que as atividades sofressem algumas interferências, já que a biblioteca ficou fechada e os ex-acadêmicos não tiveram sucesso ao tentar adentrar o recinto, o que fez com que durante as férias de verão os ex-alunos continuassem o projeto, cumprindo junto à comunidade escolar os demais dias letivos.

Dentro da seleção e revisão dos livros, teve-se a implantação de um item adicional. Por decreto do MEC, nenhum livro didático, principalmente o livro do professor, poderia estar na biblioteca. Foram separados apenas trinta exemplares de cada disciplina para uma ala especial de consulta do professor.

Um contratempo que atrasou o trabalho no projeto foi a greve das escolas da rede estadual de ensino de Santa Catarina. Por quase dois meses, o projeto precisou ficar parado, pois a escola estava fechada e ninguém poderia ter acesso ao local.

Durante este período, este projeto foi apresentado na modalidade PAINEL, no III Salão de Extensão (Figura 6).

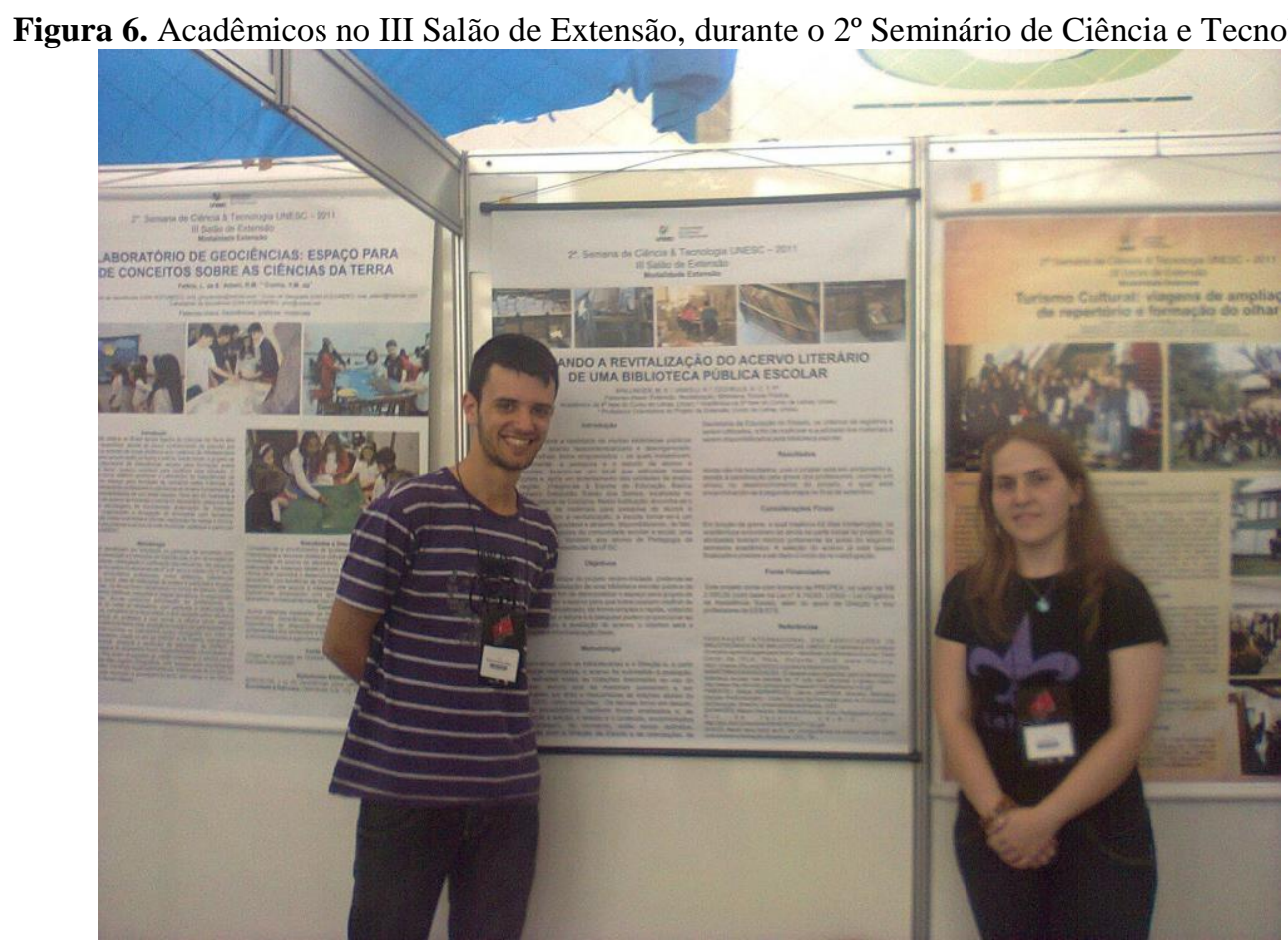

Fonte: Dos Autores, 2011. 
Após a greve, foi possível terminar a revisão do acervo, sendo feita a análise do material descartado - os que ainda se encontravam em boas condições de uso seriam destinados à doação e, os outros, à reciclagem - e, em seguida, começou-se a fase de recatalogação do acervo da biblioteca, no qual foi usado o programa Biblioteca Fácil 6.6 para informatizar todos os registros de livros. Esse processo teve uma duração de quase três (3) meses.

Para a seleção dos livros, primeiramente, foram retirados os livros didáticos a pedido do MEC. Após essa etapa, deu-se atenção aos livros que tinham sua edição muito antiga publicação abaixo do ano 2000 (vale ressaltar que os livros com edição abaixo do ano de 2000, mas que eram considerados "raridades", pois não se encontra nenhum outro igual, foram deixados no acervo); livros em desuso - folhas caindo, corroído pelo tempo, por cupins, rasgados.

O material retirado foi avaliado e os livros que estavam em uma melhor condição de uso foram doados ao Centro Educacional Marista Ir. Walmir, que atende crianças de $6^{\circ}$ ao $9^{\circ}$ anos do Ensino Fundamental, em período integral e à Escola Municipal de Ensino Fundamental Professora Maria Martins Lalau, que atende crianças de $1^{\circ}$ ao $5^{\circ}$ anos, ambas no Bairro Renascer. Os livros que estavam sem condições de uso pelos fatores já citados foram vendidos à reciclagem a fim de angariar fundos para a biblioteca. Foram vendidas cerca de 8 toneladas de livros. O dinheiro obtido foi revertido na aquisição de livros atualizados, exigidos nos vestibulares seguintes, na compra de porta-revistas, chaveiros de acrílico para o armário com escaninhos, de modo que os alunos pudessem guardar seus pertences.

Os materiais foram alocados em "bombonas" e vendidos para a reciclagem, sendo pesados e levados para o centro de reciclagem de papel do Bairro Naspolini (Figuras 7,8 e 9).

Figura 7. Pesagem dos materiais descartados

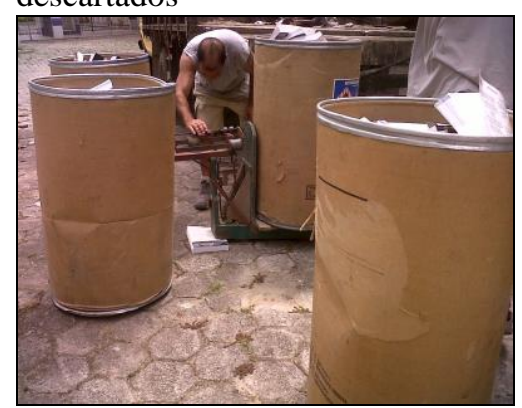

Fonte: Dos Autores, 2011.
Figura 8. Coleta dos materiais descartados

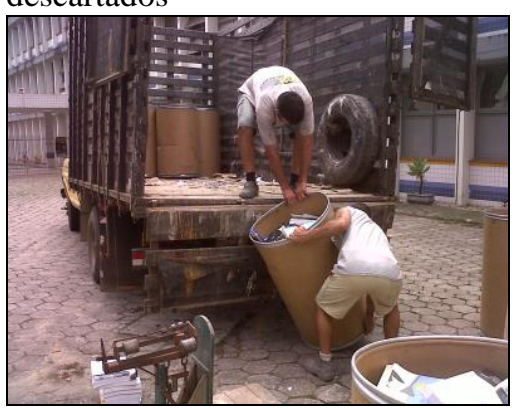

Fonte: Dos Autores , 2011.
Figura 9. Coleta dos materiais descartados

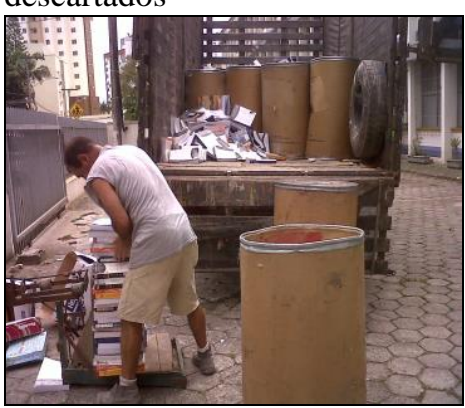

Fonte: Dos Autores , 2011. 
No total, foi vendida uma tonelada de materiais, dentre os quais havia: livros em péssimo estado; jornais antigos; materiais arquivados de feiras antigas (cartazes, trabalhos...); revistas e afins, sem mais nenhuma utilidade para docentes e estudantes.

Para a catalogação dos livros foi utilizado o programa "Biblioteca Fácil 6.6" para a catalogação de todo o acervo da biblioteca. O programa é rico em detalhes de busca e de simples utilização.

Ao todo, foram catalogados em média 9500 livros, sendo que em cada livro o registro se dava com nome do exemplar, classificação literária, tipo do item, CDU, Cutter, autor e palavras chaves. Todos esses itens têm a finalidade de proporcionar uma pesquisa rápida e eficaz e são usados mundialmente.

Vale aqui ressaltar o que é o CDU - Classificação Decimal Universal (CDU) é um projeto internacional de classificação de documentos. Baseia-se no conceito de que todo o conhecimento pode ser dividido em 10 classes principais, e estas podem ser infinitamente divididas em uma hierarquia decimal. E foi esse o modelo de classificação adotado na informatização para catalogação das obras da biblioteca da escola.

A priori, as principais divisões da CDU são:

- 0 Generalidades. Informação. Organização.

- 1 Filosofia. Psicologia.

- 3 Ciências Sociais. Economia. Direito. Política. Assistência Social. Educação.

- 4 Classe vaga.

- 5 Matemática e Ciências Naturais.

- 6 Ciências Aplicadas. Medicina. Tecnologia.

- 7 Arte. Belas-artes. Recreação. Diversões. Desportos.

- 8 Linguagem. Linguística. Literatura.

- 9 Geografia. Biografia. Historia.

Conforme avaliado desde a primeira visita à biblioteca, as estantes de livros foram remanejadas para o outro lado da sala, pois no local onde estavam era de pouca acessibilidade, estantes muito próximas umas às outras, sem condições para mais de uma pessoa estar no corredor entre elas; pouca luminosidade, fazendo com que os livros, inclusive, mofassem, deixando-os em péssimo estado, sem condições de recuperação.

As estantes também foram tiradas de seus lugares a fim de, também, arrumar algumas que estavam totalmente tortas, frouxas e enferrujadas. 
A nova organização das estantes teve como base a classificação literária do CDU Código Decimal Universal, para um fácil acesso, tanto das professoras bibliotecárias responsáveis, quando dos alunos.

Durante a realização do projeto, algumas pessoas ajudaram na realização do mesmo. Acadêmicos do curso de Letras da UNESC estiveram presentes ajudando a colocar as chamadas (etiquetas) do programa nos livros e organizar as estantes. Estes alunos trabalharam como voluntários e receberam da IES uma declaração de horas trabalhadas por estes serviços prestados.

Desde o começo do projeto, mesmo antes de iniciá-lo efetivamente, foi observado como ocorria a dinâmica diária daquele espaço e, com os próprios relatos das professoras, as quais estavam na biblioteca por afastamento da sala de aula, todas "readaptadas" por problemas de saúde; teve-se a certeza de que nenhuma tinha qualquer especialização na área de biblioteconomia. Na verdade, demonstravam, em certo ponto, desinteresse pelo trabalho e à função que estavam exercendo, avaliação feita pelo estado da biblioteca e à rejeição em querer mexer nos materiais; negando-se, inclusive, a querer desfazer-se de muitos exemplares que não faziam o menor sentido estarem ali.

Depois de implantado o programa de gerenciamento da biblioteca, alguns dos relatos obtidos foram "eu não sei mexer nisso e não quero.", apenas uma das professoras, a qual era mais nova de idade e de tempo na biblioteca, mostrou-se interessada em aprender a usar o programa.

Em uma tarde, foi dado o curso de utilização do gerenciador da biblioteca. No dia e hora marcados, apenas a professora interessada, citada anteriormente, estava presente e durante toda a explicação mostrou-se muito atenta, perguntando, mostrando vontade em aprender. No momento em que foi pedido para que ela começasse a praticar, conseguiu catalogar alguns livros, fazer empréstimos, devoluções e tudo o que o programa tinha a oferecer. No final do curso, ela relatou que "tentaria" passar para as outras professoras, mas já sabia que seria muito difícil conseguir ao menos fazer com que elas se interessassem pelo assunto, dada a resistência notada e apontada pelos acadêmicos responsáveis pelo projeto.

Quanto à utilização pelos alunos, a professora comentou que eles costumam ir à biblioteca e já começam a utilizar do programa para pesquisar os livros nas estantes. Nota-se, assim, um interesse sendo despertado nos estudantes, um dos objetivos deste projeto que, finalmente, passa a se tornar, felizmente, uma realidade na U.E. 


\section{CONSIDERAÇÕES FINAIS}

A situação em que a biblioteca se encontrava era lastimável: estantes superlotadas (e sucateadas), livros espalhados por todo o espaço físico do local, acesso restrito dos alunos ao acervo e, principalmente, ausência de profissionais capacitados para lidar com todo esse universo. Isso tudo correspondia a um imenso abismo entre este espaço de aprendizagem e os estudantes da instituição.

Em novembro de 2011, foi agendada a ida de funcionários da EEB STS - Colegião ao ao Bairro Corda Bamba/Cristo Redentor/Mina Quatro, junto à Coordenadora deste Projeto de Extensão, Nara Palácios Cechella, e feitas as doações de materiais em desuso a crianças, jovens e familiares em risco social, atendidos por outro projeto, o qual conta com o apoio do Curso de Sociologia da Unesc, em parceria com a $21^{a}$ GERED.

Este projeto ainda foi apresentado pelos ex-acadêmicos em três eventos:

1) no ECAEL $^{5}$ - Encontro Catarinense dos Estudantes de Letras, que neste ano aconteceu em Criciúma, em forma de comunicação oral (certificado está sendo providenciado), o qual ocorreu nos dias 23, 24 e 25 de setembro (o projeto foi apresentado no dia 24);

2) na Semana Acadêmica de Letras ${ }^{6}$, em forma de comunicação oral, organizado pelo Departamento de Letras da UNA HCE, nos dias 26 a 30 de setembro (o projeto foi apresentado no dia 28);

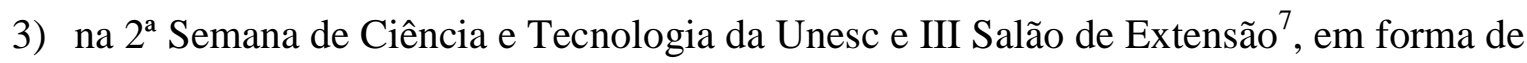
Pôster, nos dias 07 a 11 de novembro de 2011.

Os dois primeiros podem ser relembrados ao verificados no site: http://www.unesc.net/post/55/10/16714; já o terceiro evento pode ser verificado pelo site: http://www.unesc.net/post/213/11/15441.

5 CECHELla, Nara C. T. Palácios; BRILlingER, Maurício de Souza; VANOLLI, Karoline. REVITALIZANDO O ESPAÇO DE ENCANTAMENTO E BUSCA PELO CONHECIMENTO EM UMA BIBLIOTECA PÚBLICA ESCOLAR. Semana acadêmica de Letras e História e XI Ciclo de Ensino do Curso de Letras. Unesc: 28 de setembro de 2011.

6 CECHELla, Nara C. T. Palácios; BRILlingER, Maurício de Souza; VANOLLI, Karoline. REVITALIZANDO O ESPAÇO DE ENCANTAMENTO E BUSCA PELO CONHECIMENTO EM UMA BIBLIOTECA PÚBLICA ESCOLAR. ECAEL - Encontro Catarinense dos Acadêmicos de Letras. Unesc: 24 de setembro de 2011.

${ }^{7}$ CECHELLA, Nara C. T. Palácios; BRILLINGER, Maurício de Souza; VANOLLI, Karoline. INICIANDO A REVITALIZAÇÃO DO ACERVO LITERÁRIO DE UMA BIBLIOTECA PÚBLICA ESCOLAR. $2^{\mathrm{a}}$ Semana de Ciência e Tecnologia da Unesc e III Salão de Extensão Unesc - Modalidade Painel. Unesc: 2011. 
Para a realização desde projeto, foram encontrados muitos desafios. Primeiramente, pela ousada ideia em aplicá-lo na maior escola da AMREC, pertencente à rede pública estadual, a qual está entre as cinco maiores do Estado de Santa Catarina e não conta com nenhum projeto deste porte há muitos anos, por dificuldades políticas que impedem algumas atividades de serem inseridas na Unidade de Ensino.

Sanada esta primeira dificuldade e tendo a confiança tanto do Corpo Diretivo quanto do quadro de Docentes, veio em segundo lugar o desafio propriamente dito: deparar-se com um rico e gigantesco acervo de livros, totalmente em desordem, obras mal acondicionadas, acervo sem acesso dos alunos, livros novos encaixotados e muitos materiais sem registro, informações que tocaram os jovens acadêmicos de Letras, levando-os a firmar o compromisso com ainda mais vontade, de deixá-lo apropriado para receber estudantes e incentivá-los à leitura.

O projeto seguia normalmente e, após um longo período de seu andamento, algo inesperado aconteceu, uma surpreendente greve que se revelou a maior em nosso Estado. A Greve Estadual durou 60 dias e a escola permaneceu fechada. Isso atrasou e muito todo o trabalho que estava sendo realizado, inviabilizando seu término, previsto para dezembro, com vistas à escritura deste relatório e do artigo em janeiro, o que também acabou acontecendo.

$\mathrm{Na}$ volta das atividades escolares, os trabalhos foram retomados, intensificados, e os acadêmicos lutaram em período integral nos cinco dias da semana, mesmo após as aulas da universidade tendo terminado, adentrando janeiro, período de férias, na tentativa de reverter as horas perdidas em trabalho. Ainda falta uma parte da informatização do acervo, que será finalizada agora em fevereiro.

Esperava-se que, no final de tudo, depois de todos os contratempos que não eram esperados, se conseguisse cumprir com o restante das atividades planejadas. Para isso, foi feita a tentativa de envio de um novo projeto, para continuação da revitalização do espaço, com posterior proposta para a GERED, a ser executada nas demais escolas.

Este foi o motivo pelo qual se mostrou necessária a continuidade do projeto: atender, satisfatoriamente, a todos os objetivos traçados no projeto, com a complementação de mais alguns pontos, a fim de finalizá-lo por completo e garantir o benefício a toda comunidade envolvida, haja vista a importância das atividades propostas e a relevância que ele possui dentro da comunidade escolar. Vale salientar a importância para as demais escolas a serem 
contempladas com a doação dos livros, cujo público-alvo é de crianças e jovens em risco social grave.

Na medida do possível e após muito trabalho e dedicação, esse ambiente foi sendo transformado no que, de fato, deve ser a biblioteca de uma escola; livros organizados, ambiente devidamente arejado e iluminado, espaço para estudo e pesquisa, acesso ao acervo de fácil manejo e auxílio profissional especializado.

Infelizmente, a realidade de descaso e abandono da escola pública, principalmente de um dos principais espaços de aprendizagem e ludicidade - a biblioteca - é recorrente e precisa da ajuda comunitária, bem como foi a intenção desse projeto, para que esse espaço tão rico de conhecimento não seja mais uma sala destinada ao depósito de materiais e "desconhecido" da comunidade escolar.

Ter participado dessa "imersão" na realidade de uma biblioteca pública escolar foi, sem dúvida, uma experiência muito enriquecedora para a formação profissional destes acadêmicos, bem como para suas vidas, como cidadãos responsáveis pelo incentivo à educação, vista como um bem social, acessível a todos os brasileiros.

Dessa forma, nossa contribuição para a sociedade, em especial à comunidade escolar na qual o projeto foi realizado, foi promover a democratização do acesso aos bens culturais a todos os envolvidos na escola (professores, funcionários, alunos, colaboradores), contribuindo para a formação intelectual e pessoal de cada uma dessas pessoas, na tentativa de promover uma sociedade mais justa e igualitária, na qual o conhecimento não seja mais um bem acessível apenas a quem possua dinheiro, mas acessível a todos.

Este projeto contou com fomento da PROPEX, no valor de R $\$ 2.000,00$ (com base na Lei no 8.74293, LOAS - Lei Orgânica da Assistência Social), além do apoio da Direção e dos professores da EEB STS.

O projeto beneficiou mais de duas mil pessoas moradoras do bairro, de forma gratuita, sendo que os beneficiados foram: crianças e adolescentes; crianças e adolescentes vítimas de violência sexual; idosos; mulheres; portadores de deficiência; negros/ quilombolas; estudantes; adolescentes em conflito com a lei; indivíduos apenados e/ ou egressos do sistema penitenciário; família; usuários de substâncias psicoativas; comunidades locais; lideranças comunitárias e moradores de áreas de ocupação.

Em visita à escola no ano de 2016, infelizmente percebeu-se que não foi dada a devida continuidade ao projeto. Embora o ambiente estivesse mais organizado, ainda não foram 
instalados ar condicionados, nem substituídas as cortinas de pano que acabam acumulando muito pó, não foram colocados os pufes para dar mais conforto aos estudantes em momentos de leituras não-obrigatórias, tampouco os porta-livros estão sendo usados adequadamente. As placas indicativas do acervo com as numerações e códigos ainda não foram instaladas por falta de verbas, e há muitos livros novos sem catalogação no sistema. Também não há ninguém para realizar este trabalho, sendo a ida à biblioteca apenas quando a direção é procurada por algum estudante, a fim de fazer o empréstimo que voltou a ser anotado no papel, em fichas como antigamente.

Em conversa com a direção, pôde-se perceber que a falta efetiva de melhorias não ocorreu por parte desta equipe diretiva, mas por falta de interesse do próprio Estado em não remanejar profissionais específicos para este espaço, como, por exemplo, poderiam fazer com a valorização de profissionais formados em Biblioteconomia. Uma possibilidade seria a abertura de vagas para que estes possam ser inseridos em ambientes como esse, a fim de ser mais um local de efetivo trabalho escolar, não apenas mais um depósito em mais uma dentre as inúmeras escolas públicas de um país que precisa ver a educação como um investimento no ser humano, não como mais um gasto.

\section{REFERÊNCIAS}

AZEVEDO, Á. As Ideias Pedagógicas de Pestalozzi (1746 - 1827). Revista da Faculdade de Letras: Filosofia. Universidade do Porto, série I, v. 2, n. 1/2, p. 29-42, 1972. Disponível na Biblioteca Digital, em PDF. Disponível em: <http://ler.letras.up.pt/uploads/ficheiros/1283.pdf>. Acesso em: 30 nov. 2013.

FEDERAÇÃO INTERNACIONAL DAS ASSOCIAÇÕES DE BIBLIOTECÁRIOS E DE BIBLIOTECAS. UNESCO: A biblioteca no contexto do ensino-aprendizagem para todos - Manifesto da Biblioteca Escolar. Sede Geral da IFLA, Haia, Holanda: Publicado pelo Ministério da Educação de Portugal (Tradução do Gabinete da Rede de Bibliotecas Escolares), 2000. Disponível em: <www.ifla.org>; <http://www.ifla.org/VII/s11/pubs/schoolmanif.htm>. Acesso em: 14 fev. 2011.

FILHO, L. F. C. Um plano para revitalizar a biblioteca. Revista Getúlio, São Paulo, p. 56-59, 1997. <http://virtualbib.fgv.br/dspace/bitstream/handle/10438/7113/Ed3_UmPlanoPara.pdf? sequence $=1>$. Acesso em: 14 fev. 2011.

PIMENTEL, G.; BERNARDES, L.; SANTANA, M. Biblioteca Escolar. Profuncionário Curso Técnico de Formação para os Funcionários da Educação. Brasília: Universidade de Brasília, 2007.

QUINHÕES, M. E. T. Biblioteca Escolar, Ação Pedagógica e Leitura. Rio de Janeiro: UNIRIO, 19-. Disponível em: <http://docplayer.com.br/6190153-Biblioteca-escolar- 
sua-importancia-e-seu-espaco-no-sistema-educacional-do-estado-do-rio-dejaneiro.html>. Acesso em: 11 fev. 2011.

QUINHÕES, M. E. T. Biblioteca escolar: sua importância e seu espaço no sistema educacional do Estado do Rio de Janeiro. In: VIANNA, M. M.; CAMPELLO, B.; MOURA, V. H. V. Biblioteca escolar: espaço de ação pedagógica. Belo Horizonte: EB/UFMG, 1999, p. 178-182.

SILVA, O. P.; GANIM, F. Manual da CDU. Brasília: Briquet de Lemos/Livros, 1984.

SOËTARD, M. Johann Pestalozzi. Trad. Martha Aparecida Santana Marcondes, Pedro Marcondes, Ciriello Mazzetto. Recife/PE: Fundação Joaquim Nabuco, Massangana, 2010 .

SOUZA, M. J. K. et al. A importância da leitura escolar como crescimento e formação de leitores. $\quad$ UFC: 19-. Disponível em: <http://www.unirio.br/cch/eb/enebd/Comunicacao_Oral/TemaLivre/importancia_da_1 eitura.pdf $>$. Acesso em: 14 fev. 2011. 